\title{
STATISTICS AND THE POLITICS OF OBJECTIVITY ${ }^{1}$
}

Science is usually regarded as a problem of knowing, of forming theories in good accord with a stable reality. But that view is rapidly falling out of favor in science studies, in France and the English-speaking countries alike. Historians of science are rapidly being converted to what I call the new realism. The old realism, it may be recalled, held that science was about a world of objects, existing independently of the scientists. The old positivism doubted the underlying reality, but not the validity or the independence. The old constructivism proposed that the content of science has more to do with human institutions than with anything that might be called an objective world. Now the opposites have been blended into a new constructivist realism, which denies that a useful distinction is possible between society and the world, and claims that scientific knowledge is true, but chiefly in relation to a world we have constructed.

This constructivist realism has been worked out mainly in relation to laboratories. The argument sets out from Michael Polanyi's claim, develop-

1. The publication of this paper here requires some explanation. It was originally written to present as the opening talk at the February 1992 Columbia History of Science meeting in the state of Washington, USA. One of my chief aims was to introduce American historians of science to the very interesting work on the political and cultural history of statistics that has appeared in recent years in French. Owing mainly to sloth, I presented an only slightly revised version of the same talk two months later to the seminar on history of statistics at the École des hautes études en sciences sociales. Since the authors of much of the work I discussed were in the audience, this was rather like bringing fancy cheese to France. But the audience seemed interested, mainly, I think, because I constructed a unified program out of works by authors who regarded themselves as belonging to incompatible schools and traditions. There is doubtless an element of naivety here, but perhaps the foreigner's disregard of local factions has some value after all. That, at least, is my justification for allowing to be printed here my discussion of works that are readily available and well known to French scholars.

As will be immediately apparent from the footnotes, this paper is also an introduction to a series of more substantial papers of my own, most of which, as of this writing, are still in press. Their preparation was supported by the John Simon Guggenheim Foundation, the Earhart Foundation, and National Science Foundation grant DIR 90-21707.

Revue de synthese : IV $\mathrm{S} . \mathrm{N}^{\mathrm{N}} 1$, janvier-mars 1993. 
ed and refined in the last decade or two, that science depends on what he called tacit knowledge, private skill that cannot be reduced to rules and recipes, but has to be learned in a relationship of master and apprentice or at least a close association of colleagues. If this is so, then we have to ask how science has managed to claim universal validity - how, for example, experimental results can be accepted and even repeated at distant sites. One answer emphasizes the intricate network of personal contacts, of people meeting at conferences and visiting one another's laboratories, where the intricacies of technique can be picked up. Another observes that instruments and measurement systems have to a large degree been standardized. It is easier to replicate an experiment if you can buy all the equipment out of a catalogue. That is, some at least of the skills become mechanized. So manufacturing appears as a crucial element in the making of science as shared knowledge. With reliable instruments and experimental devices, the ephemeral products of skill, things like lasers and steady currents of electricity, become available to almost anybody. In a certain sense we fabricate them, but they are no less real for that ${ }^{2}$.

HOW QUANTTTIES ARE MADE VALID

I'm arguing here that quantification plays a role in the applied human disciplines akin to that of material technologies in the experimental sciences. Of course it isn't a material technology; it is, to borrow some neologisms from Steven Shapin, a literary and social technology ${ }^{3}$. Numbers form a rhetoric within disciplines, and help to order them; and at the same time they give shape to the processes they purport to describe. Numbers have power; otherwise they're ineffective. Otherwise they can't be made true 4 .

We can begin by asking about the forms of social organization that are required to make quantitative knowledge valid. These are remarkably elaborate even, indeed especially, for measures that seem to us entirely unproblematical. An exemplary set of illustrations can be found in the measurement systems created and enforced by public bureaux of stan-

2. On constructive realism, see Ian HACKING, Representing and Intervening, Cambridge, Cambridge University Press, 1984.

3. See Steven Shaprn and Simon Schaffer, Leviathan and the Air Pump, Princeton, Princeton University Press, 1985.

4. Theodore M. Porrer, « Making Things Quantitative ", Science in Context, forthcoming. 
dards. The integrity of measures depends partly on artifacts such as the platinum meter sticks sealed away far underground at Saint-Cloud, but even more on teams of inspectors who travel to markets and factories comparing liters or gallons and pounds or kilograms against a standard. Scientific communication and commercial transactions alike presuppose this activity. So also does the integrity of government, especially in regard to its regulatory functions.

An especially important and difficult measurement problem arises as a part of pollution control. Every effluent judged to be significant must have an official measurement protocol defined for it. This protocol, as J.S. Hunter observes, must define not only the instruments and reagents to use, but also sampling procedures, calibration procedures, methods of recording and analyzing data, security measures, and training of technicians. That is, materials, methods, and people atike must be adequately standardized in order to have some hope of obtaining commensurable measures from thousands or millions of factories, farms, and laboratories $^{5}$. Regular checks are needed, both to assist in the overcoming of interlaboratory bias and to provide some security against fraud, for in this domain careful, honest work will often be at odds with self-interest. Until all this is done, we can scarcely speak of quantification, even when nobody doubts that the substances in question exist as quantities.

Quite similar problems are routinely encountered in the scientific study and administration of humans. Even when the unit in question is no more problematical than a living person, it is not at all easy to enumerate a population. Population numbers will vary considerably depending on the methods specified for getting them. In the United States, there have been lively controversies about whether to incorporate the Census Bureau's own estimate of its undercount into the official numbers. For the 1990 census, the secretary of commerce decided not to, on the ground or pretext that those adjustments can never be sufficiently objective. But of course the enumeration itself is only made objective by specifying in detail what efforts will be made to locate and tally people who reside at new addresses, or who can never be found at home, or who have no fixed residence. Since census results translate directly into federal funding levels for states and cities, it is often deemed more important to have fixed and understandable rules, in order to insure fairness, than to come as close as possible to the true value.

The ideal here is a kind of objectivity. It is not the same as truth. It is more nearly identical to impersonality, or standardization. But it is an

5. J. S. Hunter, "The National System of Scientific Measurement ", Science, 210,21 nov. 1980 , p. 869-874. 
important way of making objects. When many people at different sites can produce commensurable measurements, and have some shared idea of what to do with them, then almost by definition there must be a thing, an entity, that's being measured. The power to make things is a very great power indeed. But notice that it works only if human agents are deprived of power, or at least of discretion. It is all nicely summed up in a United Nations International Development Organization economic manual, produced by Amartya Sen, Partha Dasgupta, and Stephen Marglin. The role of officials and presidents should be like that of the god of the deists : they set the machinery in motion by specifying their values as parameters, and thereafter it proceeds without political intervention ${ }^{6}$.

This preference for rules over unconstrained judgment is common both within science and in the larger political arena. The free exercise of judgment invites suspicion of arbitrariness or bias. Also, judgments will often be poorly standardized, compounding the difficulties of communication. Such considerations have inspired efforts to identify rules of right reasoning, and also to quantify judgment. Lorraine Daston shows that the theory of probability arose as a way of measuring rational belief in conditions of uncertainty. Games of chance provided readily-quantifiable analogues to practical decisions made by jurors, merchants, voters, and indeed scientists ${ }^{\top}$.

Similar aspirations can be found throughout the history of statistics. This was originally a policy science, as its etymology (" state ") suggests. In the eighteenth century, statistics was simply an empirical science of statecraft, a science whose business it was to gather up a lot of information that an absolute monarch or perhaps some governing body would find useful in administering a territory. This remained true, more or less, in the nineteenth century. But the kind of information that sovereigns felt they needed in order to govern began to change dramatically towards the end of the eighteenth century. A recent book by Marie-Noëlle Bourguet illustrates this very nicely ${ }^{8}$.

She writes about the vast statistical project that was set in motion by the Bureau de statistique in 1800 . This was a time of relative tranquility in revolutionary France, when war was not too demanding and politics comparatively benign. Unfortunately, there was no bureaucracy in place

6. Untted Nations International Development Onganization, Guidelines for Project Evaluation, New York, United Nations, 1972, p. 172.

7. Lorraine Daston, Classical Probability in the Enlightenment, Princeton, Princeton University Press, 1988.

8. Marie-Noëlle Bourguet, Déchiffrer la France : la statistique départementale à l'époque napoléanienne, Paris, Éd. des Archives contemporaines, 1988 ; also Jean-Claude Pfrrot and Stuart Woolf, Slate and Statistios in France, 1789-1815, Coire, Harwood, 1984. 
for a census so demanding as the Bureau had proposed. So when the newly-installed and badly-overworked prefects received from Paris a request for a massive compilation of information about their districts, they had to appeal to volunteers. They looked for assistance to local scholars and notables, worthy citizens whose families had been in the area for a long time and who prided themselves on their intimate sense of the traditions, customs, and produce of their regions. Their reports undertook to provide a kind of portrait, so that readers might gain a familiarity with Provence, Alsace, or Normandy only slightly inferior to what they could learn by touring the region themselves in the company of an expert guide. Where it was possible to get some numbers, say of the population or of the exports of some local commodity, the reports might supply them. But quantifying was very hard. The statistical bureau in Paris that sent out all the questionnaires had in fact wanted a lot more numerical information than it got: how much land in various categories: arable, vineyards, orchards, and meadows ; then how many cows, pigs, sheep, and fowl, and how much produce from each; how many people in all categories, and their expenses, and on and on.

Our local scholars knew a lot, but they certainly didn't have these data at their fingertips; it would have taken a whole army of census-takers to procure them. All this information couldn't have been digested anyway by the central bureaucracy even if it had been collected. Finally, and most interestingly, the regions were too diverse for their data to be aggregated : their weights and measures were different; their classifications of people were different. In short, detailed, quantitative statistical information was not only unavailable, but almost inconceivable, in 1800 ; it went against all the customs of an Old-Regime type society, and intersected in only a few points with the knowledge deemed interesting by local scholars, the only people who could provide statistical descriptions without massive bureaucratic assistance. And what is more, even the raving bureaucrats in Paris were too dreamy for the people who had to take action. The Bureau de statistique had in mind that all this information could be disseminated widely in order to educate the citizens and make them better able to maintain a liberal state. But a few years later, when Napoléon was emperor and the wars began getting more desperate again, a very different kind of information was needed. Napoléon wanted specific information for purposes of conscription, requisitions, taxes, and managing the economy for war. When he called on the Bureau de statistique, he demanded numbers for immediate use. It was unable to provide them, and soon was closed down.

Bourguet's book reveals admirably that the world was not inherently quantitative. It had to be made quantitative. This required both a disciplin- 
ed work force and a structured population. For social statisticians, the greatest problem was the lack of uniform categories. These had to be standardized among villages and regions. New categories, what Ian Hacking calls new kinds of people, had to be made up when statisticians confronted the new labor arrangements of industrial production ${ }^{9}$. Statistical categories were sometimes indistinguishable from legal ones, and might even be legally binding on nature. So an international collaboration of medical statisticians has determined what each of us will be allowed to die of, from a list of afflictions whose prototype was negotiated a bit more than a century ago. Without this standardization, public health officers would swim in a sea of uncertainty. To a large degree they still do. As Geoffrey Bowker and Susan Leigh Star show, the power of international health authorities to create and enforce a uniform classification over a world of highly diverse political and medical institutions is sharply limited. This is perhaps even more true of occupational and legal statistics. Eric Brian's work on international statistics illustrates the futility of seeking to tally up social acts according to a uniform schedule without the benefit of centralized bureaucratic power. The validity of statistical categories often extends only to the boundary of the state. In the process of enacting standards, government agencies gently remake the world they are studying. And this new world, classified and quantified, will become far more amenable to intervention by central authorities ${ }^{10}$.

\section{MAKING OBJECTS}

Social knowledge succeeds in part by creating artifacts. But this is by no means peculiar to the domain of the social. Bruno Latour has argued powerfully that making things is no less integral to science than to technology. The object of both is to construct black boxes, things that are treated as units, and that nobody is able to take apart. In his view, it serves no purpose to talk of what happens in nature, independent of human activity. Every scientific paper, every candidate fact, succeeds by mobilizing a network of allies : reagents, machines, instruments, citations, and people.

9. I. HackJng, " Making Up People », in Thomas Heller et al., eds, Reconstructing Individualism, Stanford, Stanford University Press, 1986, p. 222-236.

10. Geoffrey Bowker and Susan Leigh STAk, "Discourse in the Policy Infrastructure: Crafting the International Classification of Diseases ", in Lisa BuD-FrIERMAN, ed., Information Acumen : The Understanding and Use of Knowledge in Modern Business, London, Routledge, 1993 ; Éric Brian, a Statistique administrative et internationalisme statistique pendant la seconde moitié du xx' siècle ", Histoire et Mesure, 4, 1989, p. 201-224. 
If the network is strong a new fact is created. But it can easily break apart if any of its elements gives way. Facts, then, are artifices. Yet at the same time they are real; they become active, and can be enlisted in the networks that support new facts. Ian Hacking has also advanced a philosophy of artifactual realism. Experiments succeed when they permit the reliable manipulation of objects. Some, at least, of these objects, including particles created by high-energy physics, may very well never exist outside the laboratory. Most or all cannot be found in anything like a pure form, except by means of experiment. But if the products of one experiment - say electrons - can unproblematically be incorporated into another one, then we ought to call them real. The progress of experimental science is the increasing ability to make and use new things, and at the same time to transform the world which science purports to describe $^{11}$.

The social sciences are often regarded as pale shadows of the natural, but their power to create new entities is second to none. The public rhetoric of our time abounds in constructed quantitative entities that have taken on a vigorous life of their own. We find them in almost every domain : test scores, measures of productivity, of economic growth, of ethnic diversity and equal opportunity, of athletic prowess, and on and on. The history of statistics is an especially promising place to look for constructed entities. Statistical investigation helped to form the very notion of society : Durkheim's primal « social fact " was a statistical regularity of crime or suicide. Every statistical category has the potential to become a new thing. The tables for marriage that began to be collected around 1830 revealed that every year a small number of men in their 20 s married sexagenarian women. Here was a phenomenon that could be investigated. The curious statistician could compare the rates in different countries, or according to religious faith, or inheritance laws, in order to understand this aspect of social life ${ }^{\mathrm{l}}$.

A more commonplace statistical entity, to us, is a crime rate. Of course there were crimes before the statisticians occupied this territory, but it may be doubted whether there were crime rates. Certainly people did not talk in terms of crime rates. Hacking illustrates the point with a striking event. In 1825, John Finlaison testified before a select committee of the House of Commons that while mortality was subject to a known law of nature, sickness was not. Such a state of affairs was unacceptable to the

11. Bruno Latour, Science in Action, Cambridge, Harvard University Press, 1987 ; I. HacKING, op. cit. supra n. 2.

12. T. M. Porter, The Rise of Statistical Thinking, 1820-1900, Princeton, Princeton University Press, 1986. 
government, especially because numerous « friendly societies " of workers had undertaken to insure their subscribers against the consequences of illness. The select committee was concerned that they might soon be bankrupt. A few years later, after much further inquiry and study, laws of sickness had been consolidated. This, inevitably, was as much a problem of definition as of counting. Henceforth sickness would be well-defined. It would soon be intricately mapped out and subdivided. And the everexpanding activity of insurance administration would never again permit sickness to lapse into vagueness ${ }^{13}$.

To prevent this, the boundaries of sickness had to be policed. Otherwise insurance against the effects of illness would be impossible. Malingering is less frequently a problem in the case of life insurance. Even so, laws of mortality were as much the result of administrative exigencies as of scientific study by mathematically-informed actuaries. In Britain, for example, it is clear from a Parliamentary select committee report of 1853 that most actuaries actively opposed the imposition of uniform life tables on insurance institutions. The actuaries wanted to defend the prerogatives of their profession and their companies. The companies should have the right to keep their own records. They should build up their own mortality tables on the basis of a skilled selection of, to use their term, "quality lives ". And then a crucial element of judgment must go into the setting of premiums. The select committee wanted to override their discretion, to check their finances against a standard set of calculations. Laws of mortality were not the spontaneous effect of actuarial expertise, but political creations, designed to protect the public from losing their policies to bankrupt institutions as their high-salaried proprietors moved on to other opportunities to fleece the common man ${ }^{14}$.

The apparatus of rules required to maintain statistical entities is nicely illustrated by the whole history of accounting. This, the prototype of all quantitative professions, specializes in the use of numbers to communicate financial information. It has also created a wealth of entities : depreciation schedules, shareholder equity, return on investment, goodwill, book value, and bankruptcy, to name only a few. These are not merely ways of describing a business. They also have legal standing. They regulate how a firm can present itself to its shareholders, how it should calculate its tax obligations, and when it passes into insolvency. Management, naturally, would like the firm to look healthy and profitable to its

13. I. Hacking, The Taming of Chance, Cambridge, Cambridge University Press, 1990.

14. T. M. Porter, « Precision and Trust : Early Victorian Insurance and the Politics of Calculation ", in M. Norton Wise, ed., The Values of Precision, Princeton, Princeton University Press, forthcoming 1993. 
shareholders, and to pay as little as possible in taxes. Hence there is constant pressure from the firm's accountants and attorneys to bend the categories so that profits will apparently be up, and tax obligations will in reality go down. There are, in short, unremitting forces tending to pry these entities open. It requires a ceaseless outflow of highly detailed and explicit rules to protect them ${ }^{15}$.

Official statistical categories, like accounting definitions, occupy contested terrain. First there are problems of coding, of disciplining a workforce to put people reliably in boxes. The use of aggregate numbers to apportion political power and allocate public revenues makes it inevitable that the statistics will be disputed. Even the categories are variable. In Germany, the United States, and France, one finds three rather different categorizations pertaining to what in English are called professionals. Alain Desrosières and Laurent Thévenot discuss the political and administrative ambitions that gave rise to them. The German Angestellte, salaried employees outside the public sector, were invented at the time of Bismarck's social insurance laws so that these respectable types would not be classed with wage workers, nor represented by socialist unions. The American " professional » arose early in the twentieth century to distinguish men of knowledge committed to an ideal of service from business managers. French statisticians made up the category cadre as part of economic planning in the 1930s and 1940s. Its conceptualization and its formation were inseparable.

The dependence of categorization on particular circumstances would seem to imply that the categories are highly contingent, and hence weak. Once put in place, though, they can be impressively resilient. Legions of statistical employees collect and process numbers on the presumption that the categories are valid. Newspapers and public officials wanting to discuss the numerical characteristics of a population have very limited ability to rework the numbers into different ones. They thus become black boxes, scarcely vulnerable to challenge except in a limited way by insiders. Having become official, then, they become increasingly real. Desrosières offers a striking illustration. In 1930 nobody in France talked of cadres, or even knew what they were. A decade later the cadres could be counted. Now one can read about what the cadres think on the issues of the day, or how they dress and what they read. Increasingly, the statistical categories form the basis for individual and collective identity. Public sta-

15. T. M. Porter, "Quantification and the Accounting Ideal in Science ", Social Studies of Science, 22, 1992, p. 633-652. 
tistics are able to describe social reality in large measure because they help to define it ${ }^{16}$.

One should not suppose that numbers are useless for description. But description is inseparable from control. This need not be completely centralized, and of course it may often set in motion a process of selfcontradiction rather than affirmation. Still it works best where it has helped form the reality it aims to describe. Theodor Adorno made this argument regarding the quantitative study of culture. "When I was confronted with the demand to "measure culture ", I reflected that culture might be precisely that condition that excludes a mentality capable of measuring it. » But, he determined, this need not rule out the quantitative study of mass entertainment.

« It is a justification of quantitative methods that the products of the culture industry, second-hand popular culture, are themselves planned from a virtually statistical point of view. Quantitative analysis measures them by their own standard ${ }^{17}$.

These quantitative standards even help to fashion subjects. Numbers create and can be compared with norms, and thereby encourage people to define their own ambitions in ways that serve the goals of a large organization, such as a government, school, or business corporation. Quantitative norms are among the gentlest and yet most pervasive forms of power in modern democracies. Measures of achievement in schools and offices succeed to the degree they become, in Nikolas Rose's portentous phrase, " technologies of the soul ". They provide legitimacy for administrative actions, which rarely depend on brute force, but instead on their ability to create standards against which people judge themselves. In this way people are made governable; they display what Foucault called governmentality. That governmentality is on display both inside and outside the bounds of science ${ }^{18}$. Standards, measurements, and statistical

16. Alain Desrosiêres, « How to Make Things Which Hold Together : Social Science, Statistics, and the State ", in P. WAGNER, B. WrmRock and R. WHILEY, eds, « Discourses on Society ", Sociology of the Sciences Yearbook, 15, 1990, p. 195-218; Alain Desrosières and Laurent Thevenot, Les Catégories socioprofessionnelles, Paris, La Découverte, 1988; Luc Boltanski, Les Cadres : formation d'un groupe social, Paris, Minuit, 1982.

17. Theodor W. ADORNO, «Scientific Experiences of a European Scholar in America», D. Fleming, trans., in Donald Fleming and Bernard BAILYN, eds, The Intellectual Migration : Europe and America, 1930-1960, Cambridge, Harvard University Press, 1969, p. 338-370, p. 347,366 .

18. Graham Burchell, Colin Gordon, and Peter Mrller, eds, The Foucault Effect: Studies in Governmentality, Chicago, University of Chicago Press, 1991 ; Nikolas Rose, Governing the Soul, London, Routledge, 1990. 
analyses help to make knowledge - and rules - valid over large spaces, where face-to-face contact and close personal knowledge are impossible.

\section{EXCLUDING SUBJECTS}

The ability to make things, in sum, is central to the power of numbers and calculation in the world. It is perhaps obvious that this power contributes invaluably to the authority of statistical forms in the realm of political debate and administrative decisions. But power to create objects is only one aspect of the politics of objectivity. The other is the power to control subjects (subjectivity). Indeed, that may be the more fundamental achievement. For often it is only possible to get stable objects when the process of investigation is subjected to a tight discipline. The gathering and processing of numbers should be specified as closely as possible by rules. The exercise of judgment or discretion should be sharply curtailed. If these rules are widely respected, the numbers can claim a validity that goes beyond the people who made them up. And the existence of impersonal rules supports a claim to impartiality, a defense against charges of bias or self-interest ${ }^{19}$.

As everybody knows, the effective use of mathematics in science was achieved first in the physical sciences such as statics, geometrical optics, astronomy, and mechanics. The leadership of the physical sciences in regard to measurement is less obvious; the claims of accounting, surveying, and demography are very strong. The body of quantitative methods and concepts we know as statistics derives from mathematics, natural science, and social investigation together. Consider the methods of inferential statistics, those quantitative tools whose aim is to mechanize decisions, to reduce them to calculation. Although there are early precedents for this in astronomy, the applied, politically-sensitive sciences have generally taken the lead. Especially revealing is the now-ubiquitous statistical test of significance, which aims to make the testing of hypotheses against data a matter of mathematics rather than judgment. This was not first institutionalized in physics, the most mathematical of disciplines, but in fields like agriculture, psychology, and medicine. And within psychology, it first took hold in the highly contentious fields of mental testing and parapsychology; in medicine, in therapeutic trials. Statistical infe-

19. T, M. PorTer, « Objectivity as Standardization : The Rhetoric of Impersonality in Measurement, Statistics, and Cost-Benefit Analysis ", Ammals of Scholarship (special issue on objectivity), 9, 1992, p. 19-59. 
rence is not a matter of the methods of rational science gradually, inevitably, subduing the more rhetorical discourses of politics and administration, but a defense against politics, originating in the most suspect fields and spreading back into the purer ones. The « fight against subjectivity " that Gerd Gigerenzer identifies with the uses of statistics in psychology, is one of the main incentives for quantification generally ${ }^{20}$.

It is not only that statistical tests were not widely used in the natural sciences until rather late, but also that their use has to be understood in terms of social processes. The obvious exception to the identification of inferential statistics with social science is error analysis, an ancestor of mathematical statistics that came to be used routinely in observational astronomy in the early nineteenth century. It made the combination of observations more or less mechanical. This mechanization of judgment occurred at a time when the observatory was becoming like a little factory, characterized by a new division of labor. Seasoned astronomers had routinely discarded observations that seemed not to be of the very best quality. When less skilled employees began to do the observing, they had to be standardized, their room for judgment minimized. So they were not allowed to decide which were their best observations, but subjected to the discipline of recording them all, and then averaging them using these new forms of calculation. The most striking emblem of their standardization is the so-called "personal equation ", assigned to each observer to bring his (later often her) measurements into line with a general standard. There seems to be no simple causality here : error analysis simultaneously fed on and promoted a reduction in the status of the observer. Professional astronomers retained the right to exercise judgment, but now it rested atop a pyramid of objectified grunt work ${ }^{21}$.

An equally rich example is provided by experimental medicine. From the $1830 \mathrm{~s}$, at least, physicians had resisted what was then called the « numerical method » in medicine as too mechanical, as insufficiently appreciative of the refined judgment and tacit skills called «medical tact $»$. The triumph of statistics as a basis for therapeutic knowledge has

20. Gerd Gigerenzer, «Probabilistic Thinking and the Fight Against Subjectivity ", in Lorenz Kruger, Gerd Gigerenzer, and Mary Morgan, eds, The Probabilistic Revolution. Vol. 2. Ideas in the Sciences, Cambridge, MIT Press, 1987, p. 49-72; Kurt Danziger, Constructing the Subject : Historical Origins of Psychological Research, Cambridge, Cambridge University Press, 1990; G. Gigerenzer et al., The Empire of Chance : How Probability Changed Science and Everyday Life, Cambridge, Cambridge University Press, 1989.

21. Simon Schaffer, " Astronomers Mark Time : Discipline and the Personal Equation ", Science in Context, 2, 1988, p, 115-145; Zeno Swınnk, "The Objectification of Observation : Measurement and Statistical Methods in the Nineteenth Century ", in Lorenz Kruger, Lorraine Daston, and Michael Heidflaerger, eds, The Probabilistic Revolution. Vol. $1:$ Ideas in History, Cambridge, MIT Press, 1987, p. 261-287. 
come almost entirely since 1945 . One has to admit that it has rather enhanced than challenged the prestige of doctors. But it has cut into their discretion. In particular, making such objectified knowledge required the taming of an elite. If clinical trials and statistical analysis were to separate the effects of treatment from those of medical judgment, the physicians in an experiment had to be disciplined somehow, to be treated as mere assistants. Doctors had every reason not to be docile agents in the therapeutic trial. For ethical reasons, they could not treat the experimental subject, a sick person, as merely a vehicle for the creation of knowledge. And their professional authority was very much a matter of seasoned judgment, attuned to the idiosyncracies of the individual patient. How could the medical tact of a professional elite be subdued in the interest of statistical knowledge? The British pioneers of the controlled clinical trial accomplished this by withholding knowledge from the physicians. This was called the double-blind procedure; neither doctor nor patient should know who has received the drug under trial and who a placebo. Physicians were not reduced to a computer program, but for purposes of the experiment their interventions were neutralized ${ }^{22}$.

The political resonance of quantitative objectivity is especially well illustrated by the history of cost-benefit analysis. In France, and then the United States, cost-benefit quantification first took hold in the domain of public works ${ }^{23}$. More recently, and especially in the United States, its ambitions have become almost universal. Calculation has served partly as a tool of bureaucratic centralization, but mainly as a warrant of disinterestedness and of dedication to the public utility. None of this could be left to unfettered discretion; it had to be reduced to rules. An especially revealing example of this, admittedly an extreme one, involves assigning a monetary value to human life. Since improved safety provided one of the main reasons for flood control projects, the anticipation of lives saved could scarcely be left out of consideration. But the engineers who pioneered this form of analysis had no basis in their own disciplinary background for this sort of calculation. Their solution was to apply a convenient rule of thumb, which indeed is consistent with the spirit in which they performed most of their economic computations. They took over

22. Harry M. Marks, « Notes from the Underground : The Social Organization of Therapeutic Research », in Russell C. Maulrz and Diana E. Lovg, eds, Grand Rounds : One Hundred Years of Internal Medicine, Philadelphia, University of Pennsylvania Press, 1988, p. 297336 ; J. Rosser Matthews, Mathematics and the Quest for Medical Certainty: The Emergence of the Clinical Trial, 1800-1950, Ph. D. dissertation, Duke University, 1992.

23. François ETNer, Le Calcul economique en France, Paris, Economica, 1987; Antoine PICON, « Les Ingénieurs et la mathématisation : l'exemple du génie civil et de la construction ", Revue d'histoire des sciences, 52, 1989, p. 155-172. 
from actuaries a measure of the value of life in terms of lost earnings. The rationale for the actuarial formula, which involved a decision about how much insurance to buy, did not apply to the engineering problem, but the engineers were content to find any strategy that could promote the depoliticization of decisions about public works.

Economists, who assumed a major role in cost-benefit analysis only in the 1950s, had much more of an intellectual and professional stake in questions like the value of human life than did engineers. For them, as E.J. Mishan argued, there can be little doubt that the value of a life is not a question of production, but of preferences. A person's life is worth what it is worth to him or her. This is not a very promising basis for a quantitative solution. Economists are happy to ask instead how much compensation people require to subject themselves to certain risks. But the effects of risk are very hard to isolate, and the estimates made using the available statistics run from the tens of thousands up into the millions. So one method seems valid, but unstandardizable; the other false but standardizable. What to do? Let the theorists worry about truth. In the more applied literature, where economists are trying to offer effective policy advice about industrial regulation or drug licensing or consumer protection or medical services or freeway construction, they have often preferred to use the workable but theoretically incorrect standard of valuation of life in terms of lost productivity.

So the economists had to give up some of their most cherished intellectual values in order to fix forms of calculation that are as little dependent as possible on personal discretion. This process of standardization should be understood in terms of a sacrifice : of meanings, of judgment, of professional standards. Quantification has often involved a retreat from deep explanation in favor of adequate description and reliable manipulation. Statistics has been a consistent ally of positivism ${ }^{24}$. This implies a defensive role for numbers. Their authority must be understood according to Barry Barnes' definition : not power plus legitimacy, but power minus discretion ${ }^{25}$. Of course quantification has an important constructive role as well. As Desrosières puts it, with numbers one can make new things. But that creative role of statistics depends itself on the control of discretion.

24. T. M. Porter, "The Death of the Object : Fin-de-siecle Philosophy of Physics ", in Dorothy Ross, ed., Modernism and the Human Sciences, Baltimore, Johns Hopkins University Press, forthcoming 1993. On engineers, economists, and the value of life, see T. M. PoRTER, art. cit. supra n. 19.

25. Barty Barnes, "On Authority and its Relation to Power », in Iohn Law, ed., Power, Action, and Belief : A New Sociology of Knowledge?, London, Routledge and Kegan Paul, 1986, p. 180-195. 
This control of discretion and distrust of subjectivity points us toward one of the most important meanings of science in relation to the political and administrative order. Scientific methods signify impersonality, which is especially valued in democratic societies where personal authority and personal trust are lacking. All this suggests a sense in which the values of statistics are simultaneously the values of science and of modern society. So the growing role of science, especially of numbers, is no invasion of an alien power. It is at least as accurate to point to social pressures as providing motivation for a strict insistence on quantification within science. The pursuit of scientific objectivity embodies some of our most pervasive social values - especially those of the United States, but also, and increasingly, those of Europe as well.

Theodore M. Porter, University of Califormia, Los Angeles. 